\title{
Heterocyclic chemistry in a Blue Danube context
}

\author{
Marko D. Mihovilovic ${ }^{1}$
}

Received: 27 February 2018/ Accepted: 27 February 2018/Published online: 4 April 2018

(C) Springer-Verlag GmbH Austria, part of Springer Nature 2018

Heterocyclic chemistry has played a dominant role at the chemistry-biology interface for more than a century. The identification, characterization, and synthesis of heteroatom containing cyclic structures had a tremendous impact in many fields, such as biochemistry, natural compound chemistry, or medicinal chemistry, just to name a few. Today's understanding of complex biological processes would not be possible without the proper understanding of heterocyclic chemistry on the molecular level in nucleobase-pairing, bioisosteric relationships of bioactive compounds, enzymatic catalysis by heterocyclic cofactors, etc.- this list can be continued in many aspects. Moreover, the identification of heterocyclic materials opened the door for novel applications in organic light-emitting systems, solar panels, and many more. Quite recently, the development of bio-orthogonal concepts further expanded the application of heterocycles as diagnostic tools in modern chemical biology, again emphasizing on the cross-disciplinary role of the field and enabling a renaissance of "classical" reactions in heterocyclic chemistry in a modern context.

Consequently, the in-depth investigation of heterocyclic structures as a particular sub-area of organic chemistry proved highly inspiring on many neighboring disciplines and warranted substantial efforts in both academic and industrial context over the decades. In particular in the Central European area, several "schools" were established in the field during the second half of the 20th century. With the particular situation after WW2, there was a tremendous chasm between Western and Eastern sites with hardly any exchange of knowledge until the fall of the Iron Curtain in 1989. And even then, first contacts between academic institutions progressed rather reluctantly due to the long period of separation.

Based on the particular geopolitical and historical role of Austria, the trigger to overcome this schism in scientific intercourse in general and between schools in heterocyclic chemistry in particular came from a strategic decision by the rectorate of TU Wien in 1991. With the close proximity of the two major cities Vienna and Bratislava (only $1 \mathrm{~h}$ by car) and in light of the prospective thematic overlap of their technical universities (TU Wien and STU Bratislava), it was understood as an obvious opportunity to connect these two academic institutions as a first role model initiative. Hence, a delegation was sent from Vienna to Bratislava, and talks between the chemists involved (F. Sauter, L. Fisera, and S. Kovac, in particular) proved particularly fruitful. Driven by their curiosity to learn about progress at the other side, scientists from both countries immediately connected and engaged in fruitful exchange.

However, it became apparent that the (in)frequent exchange of individual scientists to visit each other's institutions for seminar talks would require a long period in time to really establish a robust exchange of expertise. So, soon, the idea of a regular scientific symposium in the original sense (a get-together for the exchange of knowledge in a culinary environment) was adopted and already in 1991 the first Blue Danube Symposium on Heterocyclic Chemistry (BDSHC) took place at TU Wien. Reference to the Danube was selected on purpose to underscore the common cultural and historical connection of this geographical region on an equalitarian level.

After a highly successful second edition of the meeting taking place in Czechoslovakia, the group of participating countries rapidly expanded to also include Hungary. With the peaceful separation of Czechoslovakia, the successor nations Slovakia and Czech Republic joined the group of organizing states, followed by Slovenia in 2000 to complete the current composition of the Blue Danube cercle. Since then, the meeting takes place every 2 years in one of these "Blue Danube countries".
Marko D. Mihovilovic

marko.mihovilovic@tuwien.ac.at

1 Technische Universität Wien, Vienna, Austria 


\begin{tabular}{llll}
\hline BDSHC & Venue & Year & Flagship speakers \\
\hline 1 & Vienna (Austria) & 1991 & K. Lempert \\
2 & Smolenice (Czechoslovakia) & 1992 & H. Bartsch, H. Heimgartner \\
3 & Sopron (Hungary) & 1993 & H.C. van der Plas, J. Streith, H. Wamhoff \\
4 & St. Pölten (Austria) & 1994 & H. Suschitzky, A.R. Katritzky, M. Schlosser \\
5 & Casta Papiernicka (Slovakia) & 1995 & D. Bellus, W. Oppolzer, V. Snieckus, L. Ghosez \\
6 & Brno (Czech Republic) & 1996 & D. Enders, G. L Abbe, A. McKillop, J.G. Schantl \\
7 & Eger (Hungary) & 1998 & R.S. Varma, H. Wamhoff \\
8 & Bled (Slovenia) & 2000 & A.R. Katritzky, A. Padwa, A. Dondoni \\
9 & Tatranska Lomnica (Slovakia) & 2002 & L.M. Harwood, T. Hudlicky, A. Vasella, V. Jäger \\
10 & Vienna (Austria) & 2003 & B. Sharpless (Nobel keynote), T. Bach, B. Trost \\
11 & Brno (Czech Republic) & 2005 & M. Hoffmann, I. Markó, G. Queguiner, Y. Yamamoto \\
12 & Tihany (Hungary) & T. Carell, M. Makosza \\
13 & Bled (Slovenia) & 2007 & N. De Kimpe, A.R. Katritzky, W. Kanthlehner \\
14 & Podbanske (Slovakia) & 2009 & T. Bach, J.S. Siegel, M.D. Penho e Melo \\
15 & Olomouc (Czech Republic) & 2011 & J. Cossy, E. De Clercq, T. Hudlicky, D. Sames \\
16 & Balatonalmadi (Hungary) & 2013 & L. Goossen, B. Stoltz, P. Seeberger, D. Trauner \\
17 & Linz (Austria) & V. Aggarwal, B. List, J. Mulzer, C. Nevado \\
\hline
\end{tabular}

To enable a rapid transfer of scientific information, already from the beginning keynote lectures were delivered by representatives of the participating countries (Blue Danube talks), complemented by high-ranking international flagship presentations. It was also a prime objective of the conference series to provide a platform for young scientists and students, in particular. This aspect was further strengthened in the new millennium by nominating at least one young investigator from each country as Blue
Danube speaker, which became an attractive brand of the conference. Since then, the symposium series provides a highly inspirational and vibrant atmosphere of scientific intercourse in all areas of heterocyclic chemistry and attracts participants from the whole central and Eastern European area. With the most recent edition in Linz in summer 2017, completion of the first quarter century was celebrated for this role model initiative to integrate the European scientific scene in chemistry.

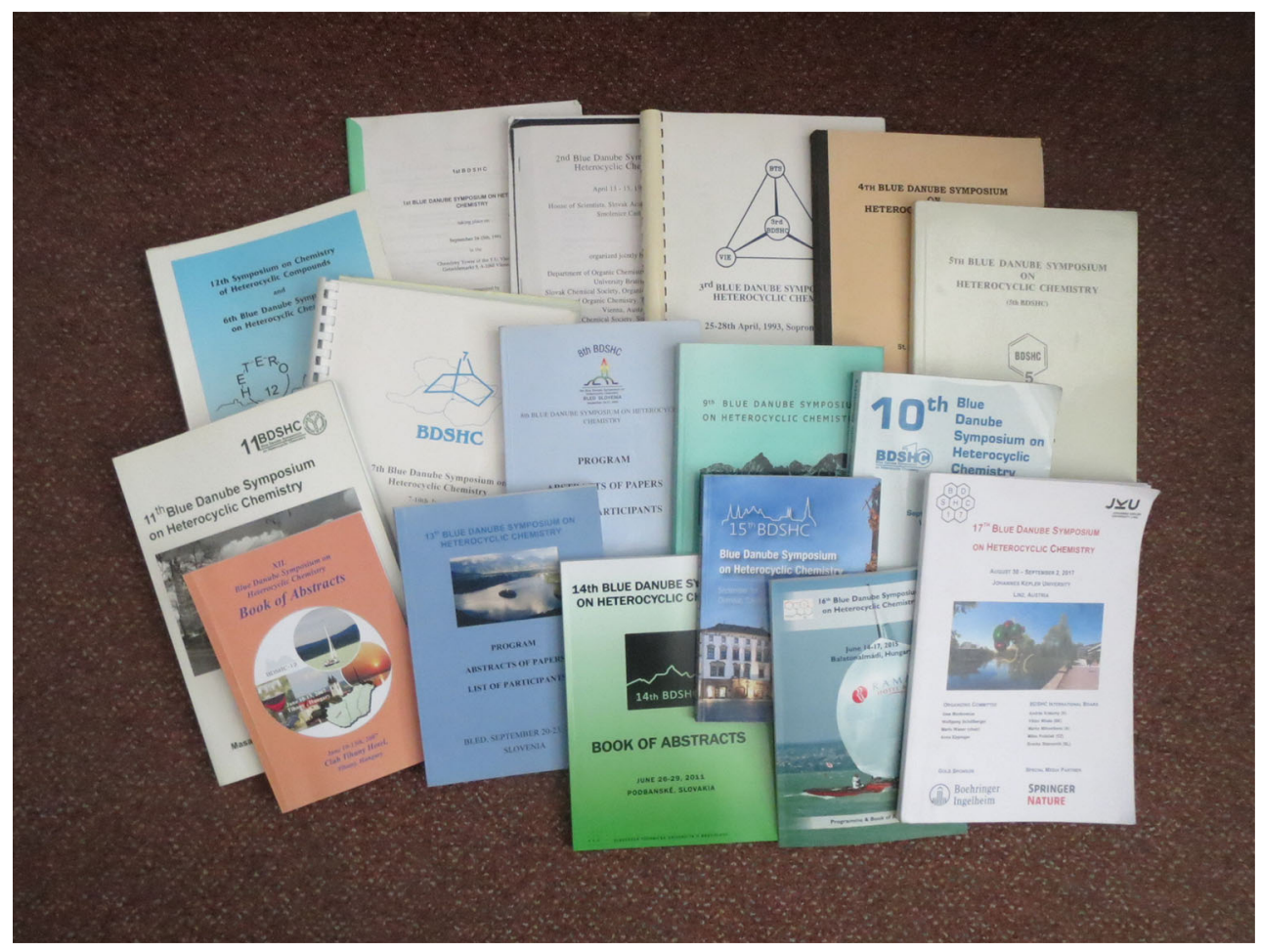


This special issue of Monatshefte contains a representative compilation of contributions to the previous BDSHC in Linz and demonstrates the breath and diversity of modern heterocyclic chemistry. It also reflects the substantial progress achieved in this geographical area fostered by the idea to bring together scientific cultures that were artificially separated for a long period of time. It was this idea to overcome barriers, which was incepted and implemented by the founders of the Blue Danube cercle.
May the next generation continue to keep up this spirit of a pan-European research area.

Past and present members of the BDSHC steering board: Lubor Fisera (Slovakia, past), Stefan Kovac (Slovakia, past), Johannes Fröhlich (Austria, past), György Hajos (Hungary, past), Andras Kotschy (Hungary, present), Marko D. Mihovilovic (Austria, present), Viktor Milata (Slovakia, present), Milan Potacek (Czech Republic, present), Fritz Sauter (Austria, past), Branko Stanovnik (Slovenia, present). 